\title{
Impacts of Operational Failures on Primary Care Physicians' Work: A Critical Interpretive Synthesis of the Literature
}

Carol Sinnott, $M B, B A O, B C b$, MMedSci, PbD, MICGP, MRCPI ${ }^{1}$

Alexandros Georgiadis, MSc, PgDip, $P h D^{1,2}$

Jobn Park, MB, CbB

Mary Dixon-Woods, DPhil

${ }^{1}$ THIS Institute (The Healthcare Improvement Studies Institute), University of Cambridge, Cambridge, United Kingdom

${ }^{2}$ ICON Plc, The Translation \& Innovation Hub Building, Imperial College London, LondonUnited Kingdom

${ }^{3}$ Harvard T.H. Chan School of Public Health, Boston, Massachusetts

\section{Shen MORE ONLINE www.annfammed.org}

\begin{abstract}
PURPOSE Operational failures are system-level errors in the supply of information, equipment, and materials to health care personnel. We aimed to review and synthesize the research literature to determine how operational failures in primary care affect the work of primary care physicians.

METHODS We conducted a critical interpretive synthesis. We searched 7 databases for papers published in English from database inception until October 2017 for primary research of any design that addressed problems interfering with primary care physicians' work. All potentially eligible titles/abstracts were screened by 1 reviewer; $30 \%$ were subject to second screening. We conducted an iterative critique, analysis, and synthesis of included studies.
\end{abstract}

RESULTS Our search retrieved 8,544 unique citations. Though no paper explicitly referred to "operational failures," we identified 95 papers that conformed to our general definition. The included studies show a gap between what physicians perceived they should be doing and what they were doing, which was strongly linked to operational failures-including those relating to technology, information, and coordination-over which physicians often had limited control. Operational failures actively configured physicians' work by requiring significant compensatory labor to deliver the goals of care. This labor was typically unaccounted for in scheduling or reward systems and had adverse consequences for physician and patient experience.

CONCLUSIONS Primary care physicians' efforts to compensate for suboptimal work systems are often concealed, risking an incomplete picture of the work they do and problems they routinely face. Future research must identify which operational failures are highest impact and tractable to improvement.

Ann Fam Med 2020;18:159-168. https://doi.org/10.1370/afm.2485.

\section{INTRODUCTION}

AC Annals Journal Club selection; see inside back cover or http://www.annfammed.org/site/AJC/.

Conflict of interest: authors report none.

\section{CORRESPONDING AUTHOR}

Carol Sinnott, MB, BAO, BCh, MMedSci, PhD, MICGP, MRCPI

THIS Institute (The Healthcare Improvement Studies Institute)

Clifford Allbutt Building

Cambridge Biomedical Campus

University of Cambridge

Cambridge, UK CB2 OAH

cs926@medschl.cam.ac.uk
$\mathrm{H}$ igh-quality health care depends on well-functioning operational systems that ensure that what is required to meet patient needs is in the right place at the right time. ${ }^{1}$ Operational failures, defined as system-level errors in the supply of necessary materials, equipment, or information to employees, ${ }^{2}$ frequently frustrate health care professionals efforts to care for their patients. These failures (eg, no thermometer probe covers in stock; searching for missing devices, reordering incorrect medicines sent to ward, etc) have been well-studied in the hospital literature, revealing that cumulative time losses associated with even minor recurrent failures are significant. ${ }^{2-4}$ By degrading individual and organizational performance, operational failures complicate the delivery of high-quality care, with multiple adverse consequences for patient safety and experience, efficiency, and worker satisfaction. ${ }^{2,3}$

Since operational failures are potentially tractable to improvement, for example through work systems and process redesign ${ }_{,}{ }^{4}$ it is important that they are recognized and addressed. The challenges associated with 
operational failures have, however, received far more attention in the hospital research literature than in the primary care literature. This is problematic because failings that affect the ability to provide safe, high quality care are likely to be highly consequential in primary care, where the majority of health care contacts occur ${ }^{5,6}$ and where escalating workload, unprecedented levels of stress, and a crisis in recruitment and retention are major threats to sustainability. ${ }^{7,8}$

In this article, we report a review that sought to produce a synthesis of the existing research literature on operational failures in primary care, with the aim of optimizing learning from studies thus far. We sought to move beyond simply cataloging the failings described in the literature to characterizing how they affected primary care physicians' work.

\section{METHODS}

We conducted a critical interpretive synthesis, ${ }^{9}$ a method that seeks to incorporate elements of conventional systematic reviews with an interpretive and critical approach to analysis, allowing synthesis of complex, diverse bodies of literature, and that is especially suited to theory generation. In this approach, processes of question formulation, searching, selection, data extraction, critique, and synthesis are characterized as iterative, interactive, dynamic, and recursive rather than as fixed procedures in a predefined sequence. Searching and selection of relevant articles was undertaken systematically, but the main focus of our analysis, consistent with the critical interpretive synthesis approach, was conceptual development rather than data summary.

\section{Formulating the Review Question}

We formulated our review question iteratively in response to initial search results and early findings. We began by using "operational failures" as a sensitizing concept ${ }_{1}^{10}$ using the definition that had been developed in the context of hospital medicine: "system-level errors in the supply of necessary materials, equipment, or information to employees." 2 Our initial sweep of the literature identified that the term "operational failures" was absent from the primary care literature. However, many studies reported problems that conformed to the general definition. After team discussion, we devised the exploratory review question: "What problems can be identified in the literature as representing operational failures in primary care and how do these problems affect primary care physicians' work?" Further, given the system-level characteristics of operational failures, we specified "system" holistically to include anyone or anything a primary care physician must interact with in order to perform their work. ${ }^{6}$

\section{Searching the Literature}

We developed our search strategy in collaboration with a medical librarian (search protocol in Supplemental Appendix 1, http://www.AnnFamMed.org/ content/18/2/159/suppl/DC1). We searched 7 databases (Table A1, Supplemental Appendix 1), as well as gray literature to find citations that addressed organizational problems, supply errors, disruptions, and interruptions in primary care from database inception until October 17, 2017. The search was conducted by author J.P. We did not restrict our search by study design or method.

\section{Developing the Inclusion and Exclusion Criteria}

We developed our inclusion and exclusion criteria (Table 1) to capture empirical studies of problems that represented operational failures in primary care. The principal inclusion criterion, that a study described how a problem affected primary care physicians' work, helped to distinguish the literature of interest from adjacent literatures on adverse events, medical errors, quality and safety, task distribution, and workflow that were not strictly relevant to our goals.

\section{Table 1. Inclusion and Exclusion Criteria}

\begin{tabular}{|c|c|}
\hline Inclusion Criteria & Exclusion Criteria \\
\hline \multirow{4}{*}{$\begin{array}{l}\text { Set in primary care, general } \\
\text { practice, or similar settings } \\
\text { Focused on the work of pri- } \\
\text { mary care physicians or their } \\
\text { equivalent internationally }\end{array}$} & Set in secondary or tertiary care or hospitals \\
\hline & Focused on secondary care or subspecialty physicians, or \\
\hline & $\begin{array}{l}\text { other health care professionals in primary care who are not } \\
\text { physicians }\end{array}$ \\
\hline & Focused on the entire organizational system of primary care at \\
\hline \multirow{2}{*}{$\begin{array}{l}\text { Presented empirical data or } \\
\text { primary research }\end{array}$} & a regional, state, or national level \\
\hline & Based in out-of-hours services, community hospitals, or spe- \\
\hline \multirow{7}{*}{$\begin{array}{l}\text { Described the impact or } \\
\text { effect of the potential } \\
\text { operational failures (related } \\
\text { terms include disruptions, } \\
\text { distractions, breaks-in-task, } \\
\text { interruptions, situational } \\
\text { constraints etc) on the pri- } \\
\text { mary care physician }\end{array}$} & cialty clinic care in the community \\
\hline & Lacking empirical data (ie, theoretical discussions, editorials etc) \\
\hline & Not published in English \\
\hline & $\begin{array}{l}\text { Examined practice responses to new policy initiatives without } \\
\text { examining if/how these initiatives were problematic for pri- } \\
\text { mary care physicians }\end{array}$ \\
\hline & $\begin{array}{l}\text { Focused on adverse events, errors, quality and safety, quality } \\
\text { improvement, or task-distribution without problematization } \\
\text { of issues from the perspective of primary care physicians }\end{array}$ \\
\hline & $\begin{array}{l}\text { Focused on the implementation of novel innovations/interven- } \\
\text { tions as part of a program of research }\end{array}$ \\
\hline & $\begin{array}{l}\text { Focused only on productivity without identifying or describing } \\
\text { specific problems that interfere with efficiency }\end{array}$ \\
\hline
\end{tabular}




\section{Sampling}

Once all results had been saved, each citation was screened, facilitated by Endnote software. One author (J.P.) reviewed titles and/or abstracts for all citations retrieved. Two authors (C.S., A.G.) undertook second screening of $15 \%$ of the total set of citations each, meaning that $30 \%$ of the entire set received a second screening. The results from each reviewer were discussed and compared in a daylong team meeting. We did not undertake a formal test of interrater agreement, but all of the articles deemed potentially relevant by C.S. and A.G. $(n=130)$ had also been deemed potentially relevant by J.P. in his screen of the whole data set, suggesting high reliability. A highly inclusive approach to full-text retrieval was used to ensure that any potentially eligible article was considered. Two reviewers (C.S., A.G.) assessed all full texts independently and resolved discrepancies in inclusion decisions by consensus.

\section{Determination of Quality}

We assessed all studies using the 5 quality criteria (Table A2, Supplemental Appendix 1) described in the original account of critical interpretive synthesis $^{9}$ and, consistent with the approach, only excluded papers with major methodological limitations that were deemed "fatally flawed." This resulted in exclusion of 2 papers that would otherwise have been included on the basis of relevance (journalistic-style papers).

\section{Data Extraction}

We extracted prespecified information on study setting, design, sample, and key findings (qualitative and numerical) on what and how failings in primary care work systems affect primary care physicians' work using a template (Table A3, Supplemental Appendix 1) We used shared tables in GoogleDocs for data extraction. Key findings were imported into NVivo 11 to facilitate data analysis. ${ }^{11}$

\section{Analysis and Synthesis}

We began by inspecting papers' key findings, identifying recurring issues and generating themes across papers. As part of this process, we updated and refined the categories of operational failures in hospital nursing proposed by Tucker et $\mathrm{al}^{2,3}$ (Table 2) to better account for issues evident in our data.

Using authorial skills, ${ }^{12}$ we undertook a critique of the entire corpus of data and characterized the impacts of operational failures on primary care physicians' work. This analysis was aimed at the development of a synthesizing argument ${ }^{9}$ : a critically informed integration of evidence from across included studies. This analysis involved the generation of synthetic constructs (new constructs generated through synthesis) that, where appropriate, drew on relevant literatures from social science and engineering-for example, relating to emotional labor, which describes how management and regulation of emotions may be a work requirement for many occupational groups ${ }_{1}^{13}$ and resilience engineering, which describes the difference between work-as-done vs work-as-imagined. ${ }^{14}$ As a team, we met to engage reflexively with findings at each stage and to discuss how material would be handled. We secured dependability by seeking evidence of repetition or saturation of themes and thorough iterative analysis.

\section{RESULTS}

Our bibliographic searches identified 8,544 unique citations. We retrieved 372 full-text articles, of which 95 studies satisfied our inclusion and exclusion criteria (Figure 1).

\section{Critical Summary of the Literature}

As noted in the Methods section, a perhaps remarkable feature of the literature on primary care physicians' work is the limited explicit attention given to operational failures. Further, even when studies address what might on the face of it appear to be operational failures, they often do not examine the impacts of those failures on physicians. Thus, we excluded over 200 studies because they did not examine the effects of suboptimal work systems on primary care physicians. For example, 48 papers identified discrepancies in patients' medication lists at transitions of care as a frequent problem, but $44 \mathrm{did}$ not refer to the impact on or work required of primary care physicians to resolve the discrepancies and were thus excluded. Even among included studies, few quantified the specific impacts of

\begin{tabular}{|c|c|}
\hline $\begin{array}{l}\text { Categories of Operational } \\
\text { Failure Experienced by } \\
\text { Hospital Nurses }{ }^{2}\end{array}$ & $\begin{array}{l}\text { Measure of Impact of } \\
\text { Operational Failures on } \\
\text { Hospital Nurses }^{3}\end{array}$ \\
\hline Medication & Number of additional tasks \\
\hline Supply items (including food) & Direct time consumed \\
\hline Medical orders & Indirect time consumed \\
\hline Equipment & Interruptions \\
\hline Insufficient staffing & Direct delay \\
\hline \multirow[t]{4}{*}{ Other } & Indirect delay \\
\hline & Risk \\
\hline & $\begin{array}{l}\text { Number of people contacted to } \\
\text { resolve problem }\end{array}$ \\
\hline & $\begin{array}{l}\text { Losses including wasted materi- } \\
\text { als and loss of confidence in } \\
\text { organization }\end{array}$ \\
\hline
\end{tabular}




\section{Figure 1. Flow diagram of search.}

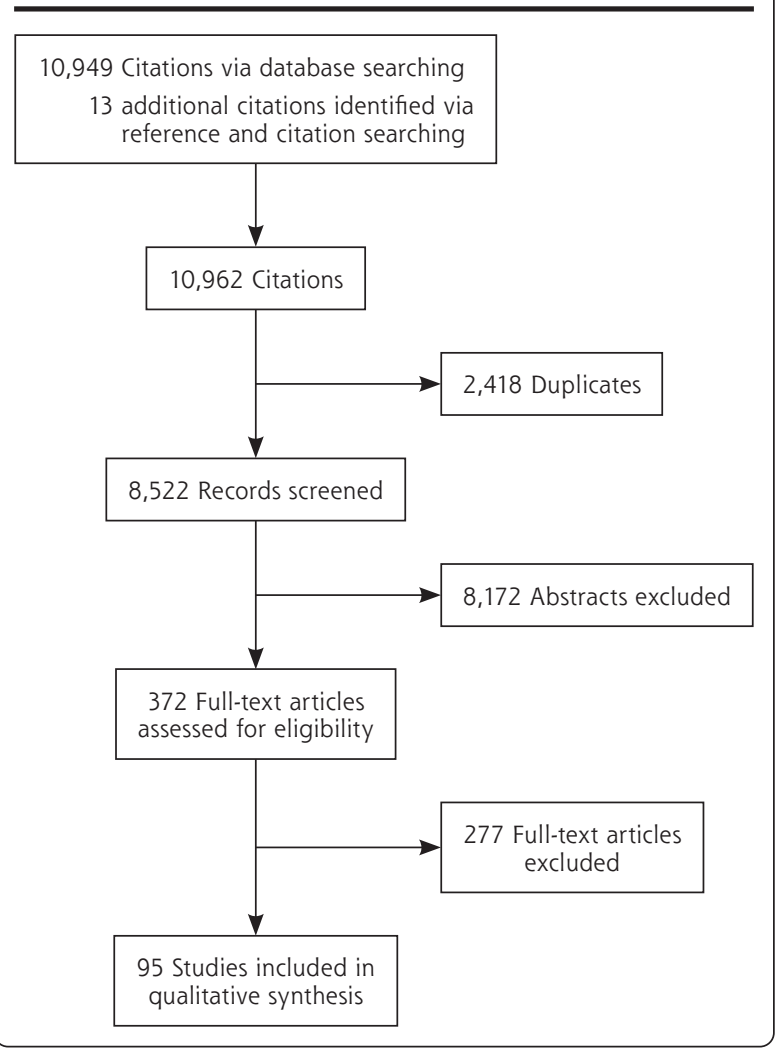

operational failures, instead tending to focus on generalized metrics such as physician satisfaction.

An overview of the 95 included studies is provided in Table A4, Supplemental Appendix 1. In summary: 39 were qualitative, 38 quantitative, 15 mixed-method, and 3 were reviews. Most studies came from the United States (65), followed by the United Kingdom (12), Canada (5), Ireland (3), Israel (2), and 1 each from Australia, Cyprus, Malaysia, New Zealand, Norway, Singapore, Spain, and the United Arab Emirates.

The most frequently reported operational failures related to information technology, with accounts of problems with electronic health records $(n=19$ studies), computer decision support systems (18), e-prescribing (9) and e-referral systems (3). Failures in practice processes were the next most frequent focus, and mostly related to inefficient channeling of information through the practice (30) or inefficient material supplies (3). Fewer studies dealt with operational failures arising from secondary care, such as suboptimal communication of patient information (7), medication discrepancies (4), and flawed systems for patient testing (2). The impacts of the operational failures (Table 3) included consuming time, disrupting task completion, delaying clinical decisions, and interfering with the doctor-patient relationship.
Synthesizing Argument: Operational Failures Configure Primary Care Physicians' Work and Require Compensatory Labor

Our synthesizing argument is that operational failures contribute to how primary care physicians' work is configured, much of the effort to address work-asconfigured can be characterized as compensatory labor, involving multiple mundane and frustrating tasks that often remain invisible and undervalued, but are essential to delivering on the obligations of physicians' professional role. This argument mobilizes 2 synthetic constructs: work-as-configured and compensatory labor, which we elaborate on below.

The literature suggests that operational failures are pervasive in primary care physicians' daily work. The failures described were characteristic of what Hollnagel describes as the gap between "work-as-imagined" (work as it ought to be) and "work-as-done."14 An important feature of the literature we examined was how the gap between what physicians perceived they should be doing and what they were doing was to a large extent actively organized by operational failures over which they themselves often had very limited control. We generated the synthetic construct of "work-as-configured" to describe how operational failures structured work-as-done.

Further reflecting Hollnagel's suggestion that complex systems like health care only succeed because of resilience of responses to imperfect work conditions, ${ }_{1}^{15}$ we found that work-as-configured compelled physicians to take action to compensate for the suboptimal systems in which they worked. ${ }^{15}$ Pivoting from the notion of "emotional labor,"13 which was developed to describe how the management and regulation of emotions may be a work requirement for many occupational groups, we generated the synthetic construct of "compensatory labor" to describe the demand for primary care physicians to undertake additional work in response to work-as-configured. Compensatory labor was essential for primary care physicians to fulfill their duties of overseeing, coordinating, and safeguarding patients' care, yet was not usually clinical in character. Instead, it tended to involve characteristically mundane tasks (eg, chasing information from hospitals, resolving technology malfunctions; Table 3). Physicians perceived much compensatory labor as distracting and detracting from their proper work with patients.

The mundane nature of compensatory labor surfaced repeatedly, for example, in studies of technologyrelated tasks. Poorly designed technologies configured work via slow running speeds, time-consuming searches for information within electronic records, or requirements for duplicated data entry ${ }^{16-41}$ perhaps as a consequence of technologies being designed around 
Table 3. Impact of Operational Failures on Primary Care Physicians" Work and Examples Associated With These Impacts

\section{Impact of Operational \\ Failure on Primary \\ Care Physicians}

1. Additional steps required to complete task

2. Required workarounds

3. Consumed time

4. Disruptions

5. Delayed decision making

Interfered with physician-patient relationship

7. Cognitive burden

8. Dissatisfaction

\section{Examples}

- Double documentation; duplicating, and repeating notes if no link between notification system and patient's record

- Work shifting to primary care physicians that was previously done by others (eg, filling in forms, scheduling patients, updating patient contact information)

- "Looping" of tasks between clinical and nonclinical teams due to uncertainty over roles within practice

- Separating prescription items into those that can be prescribed electronically and those needing "wet-signatures"

- Contacting other professionals, insurance, or billing systems for missing information or patients themselves for answers if information in record is thought to be inaccurate or is difficult to find

- Using paper-based tracking systems of ordered tests, prescriptions issued, abnormal test results, etc because electronic health record does not facilitate this tracking

- Copying and pasting text from patient's previous notes if system does not auto-populate new templates

- Printing out notes owing to difficulties in switching between computer screens

- Disabling or ignoring electronic health record functions

- Hand-writing prescriptions or test requests if information technology networks go down or if want to add additional details that are not permitted within electronic systems

- Manually inputting information if poor interoperability between systems

- Opening information systems that freeze or lock physician out

- Removing repetitive or unnecessary alerts

- Searching for missing test results or repeating tests

- Interruptions to consultation from staff, other patients, phone calls

- Interference to workflow by computer decision support alerts taking physician into other tasks

- Having to leave room to get necessary equipment, find paper for the printer, or use a different printer

- Not having access to required examination rooms

- Lack of information feedback from and difficulty reaching other health care clinicians

- Missing or delayed test results

- Trying to determine who should undertake pending tests

- Not being able to locate necessary information in the notes

- Poorly designed electronic health records shifts physicians' focus away from the patient

- Addressing clerical or administrative questions with patients during consultations shifts focus away from their presenting complaint, and consumes time

- Information overload due to multiple streams of incoming patient information, with most relevant information obscured by repetitive or unnecessary information

- Decision support systems creating unhelpful signal-noise ratio with clinically irrelevant alerts and alert fatigue

- Frustration associated with delayed or missing critical information from other clinicians, laboratories, etc

- Stress arising from disruptions during the consultation, inefficient practice organization, and hectic schedules

- Dissatisfaction associated with large volumes of non-clinical tasks

- Time pressure and work pace leading to stress and burn-out the needs of administrators, regulators, and insurance providers rather than physicians. ${ }^{16-18,20,42,43}$ Similarly, the daily work of repeat prescribing was frequently interrupted by problems including incorrect information in electronic formularies, out-of-date medication histories, and prescriptions "going missing" on their journey between practice and pharmacy, leaving physicians to undertake additional work to fulfil their duties to the patient. $17,35-38,40,44-51$

\section{Primary Care Physicians' Nodal Position and Work- as-Configured}

Primary care physicians occupied a nodal position among multiple interacting but fragmented components of the health system (the patient, secondary care, community care, pharmacy etc). This nodal position required them to integrate scattered information to produce plans for patient care, ${ }^{52-58}$ and led to the frequently reported operational failure of "information discontinuity." For example, discharge and outpatient letters from secondary to primary care physicians were delayed, ambiguous, or absent in up to $77 \%$ of patients, ${ }^{52,53,56,59-62}$ and letters that did arrive often lacked detail about in-patient treatment ( $7 \%$ to $22 \%$ ), test results $(65 \%)$, patient counseling $(90 \%$ to $92 \%)$, or follow-up plans ( $2 \%$ to $43 \%)$ ). $47,52,53,60$ Information discontinuity hindered physicians' ability to implement clinical decisions, ${ }^{52,56,59,60,63}$ to which they generally responded by taking multiple compensatory steps to find the missing information. ${ }^{53}$

"Information overload" arose from physicians' responsibility to review all patient-related information. US physicians received approximately 60 notifications from other care clinicians daily, ${ }^{64-}$ ${ }^{67}$ and though many were for trivial nonclinical issues, physicians 
reported anxiety about missing critical information among the many notifications received. ${ }^{64}$ "Information scatter" described health records cluttered with entries from other health care clinicians. ${ }^{21,44,66,68}$ Difficulties finding "buried" information"21,23,34 led many physicians to simply ask patients for required information instead ${ }^{23,32,36,44,68}$, while others kept memos for themselves on complex cases, or developed tracking systems for important outgoing correspondence, prescriptions, and test requests. $16,19,20,22,25,27,29,30,32,36,44,47,57,63,65,67-69$

\section{Amplification of Compensatory Labor by Suboptimal Task Distribution and Delegation Within Practices}

Although up to $80 \%$ of primary care physicians' tasks were potentially "do-able" by other practice staff, physicians tended to retain ownership of response to operational failures. ${ }^{16,47,67,70-72}$ Work-as-configured was an important explanation for this low level of delegation. External agents determined that certain administrative tasks (eg, obtaining insurance authorization, contacting laboratories for test results) must be completed by physicians. ${ }^{25,48}$ Within practices, delegated tasks could "loop" between clinical and clerical staff, often creating more work for the physician and delaying task completion. ${ }^{70}$ Intended improvements in practice processes sometimes inadvertently lead to more work for physicians. ${ }^{16,20,73-76}$ For instance, the adoption of electronic health records meant that tasks previously done by clerical staff were now being left to physicians: "Earlier I dictated referrals. Now I type them myself." $16,18-20,27,28,32,43,48,68,70$

\section{Compensatory Labor is Invisible and Unrewarded}

A unifying feature of many operational failures was that they were unaccounted for in primary care work systems, which were typically based on work-asimagined and did not encode the requirement for compensatory labor. Hidden from view, little valued, and unrewarded, compensatory labor shared similarities with Allen's construct of "organizing work," which describes the everyday work nurses do to coordinate and organize patient care, much of which goes unnoticed and uncounted. ${ }^{1}$ Primary care physicians regularly fell behind schedule due to unpredictable operational failures that occurred within consultations, ${ }^{24,47,67,72,77-79}$ including repetitive, clinicallyirrelevant electronic alerts that distracted physicians from patients' primary clinical issues, ${ }_{1}^{19,21,22,42}$ pushed them into dealing with other tasks, ${ }_{1}^{24,33,37,38,53,78,80-84}$ and crowded their ability to think. ${ }^{24,26,38,42,46,66,80,82-91}$ Nine studies portrayed interrupted consultations (manifesting as phone calls or questions from other staff) as operational failures, ${ }^{92-100}$ that could affect from $5 \%$ to $90 \%$ of consultations.

As a consequence of the obscuring of compensatory labor and insufficient time to complete tasks elsewhere during the working day, consultations often ran longer than allocated. However, practices did not change physicians' schedules to allow for these pressures, resulting in a problem labeled by Chesluk et al as the "fictive schedule." ${ }^{172}$ The fictive schedule pushed compensatory labor into the interstices or out-ofhours, which further contributed to stress, low job satisfaction and burnout. ${ }^{16,47,48,67,68,70,72,77,101-104}$

\section{DISCUSSION}

Our interpretive overview of 95 studies has identified multiple problems in operational systems in primary care. These operational failures, combined with the role of primary care in synthesizing information and coordinating care, actively configure the work that physicians have to do to care for their patients, requiring significant compensatory labor to deliver on the goals of care. Often invisible and unaccounted for in scheduling or reward systems, compensatory labor typically involves mundane tasks that crowd clinical work and lead to unwanted consequences such as physician-stress and burnout. ${ }^{70,105}$ We further identified that even the research literature itself obscures workas-configured, often identifying problems but not their impact on the work of physicians. Limitations in the evidence therefore risks presenting an incomplete picture of the work done by primary care physicians and the problems they routinely face, and of diminishing opportunities to improve the primary care work environment. Based on our findings, we concur with others that adding more physicians into broken systems is unlikely to solve the primary care crisis on its own: what is also needed is significant investment in improving the primary care work environment. ${ }^{48,106}$

\section{Recommendations for Practice, Policy, and Future Research}

These findings have important implications for practice and policy, suggesting that renewed attention to basic operational systems in primary care, including how these systems interact with others in the health and social care ecosystem, is much needed. Unless these challenges are addressed, bold efforts at practice redesign (eg, the Chronic Care Model, the patient-centered medical home, and more recently, in the United Kingdom, the NHS General Practice Development Programme) may flounder. ${ }^{32,107}$

Our findings also raise important questions for research. Hollnagel has suggested that studying the 
everyday performance adjustments made in the context of work conditions can highlight some of the challenges associated with complex systems like health care. ${ }^{15}$ Yet we found no papers that looked holistically at all aspects of primary care physicians' work environment, limiting the ability to identify most critical operational failures, the overlaps or knock-on effects. ${ }^{20,21,23}$ Without closer examination of how the overall health system supports primary care and the "basic science" of what happens in primary care practice, efforts to improve operational systems themselves risk limited success. ${ }^{32}$

\section{Strengths and Limitations}

A Critical Interpretive Synthesis approach offered what a traditional systematic review could not: the ability to reframe and reinterpret existing literature through a synthesizing argument that could generate new insights and highlight research gaps ${ }^{9}$ Our multidisciplinary team supported reflexivity throughout the review process and guarded against framing of the analysis according to a single perspective, as did allowing the research question to be defined emergently rather than a priori. We further enhanced trustworthiness by searching multiple databases and using inclusive search terms, and achieved confirmability through team reflexivity and documentation of decisions.

Given the range and number of topics covered by our review, it is possible that we may have missed relevant studies. However, as our goal was conceptual saturation rather than finding every conceivable paper on a topic, we feel this pragmatic trade-off was acceptable. A further limitation of our study inheres in the literature itself and the research questions it has chosen to address: for instance, the dominance of technology papers is likely an artifact of the 2009 US legislation that incentivized physicians to use electronic records to achieve improvements in care, and may not reflect the true prevalence, nature, or range of impacts of operational failures in primary care.

\section{Conclusions}

Our synthesis of the literature demonstrates that operational problems in primary care configure the work of primary care physicians, requiring them to engage in compensatory labor to safeguard patient care. Future research must look more closely at the primary care work environment to determine which operational failures have the highest impact and which to prioritize for improvement. Practice and policy should recognize the significance and impacts of system-level operational failures on the work of physicians and the experiences and outcomes of patients.

To read or post commentaries in response to this article, see it online at http://www.AnnFamMed.org/content/18/2/159.
Submitted January 8, 2019; submitted, revised, July 11, 2019; accepted July 22, 2019.

Funding support: This work has been supported by an NIHR (UK) Clinical Lectureship (C.S.), an Academy for Medical Sciences (UK) Starter Grant (SGL01811023) (C.S), and a Wellcome Trust Senior Investigator Award (WT09789) (M.D.-W.). M.D.-W. is supported by the Health Foundation's grant to the University of Cambridge for The Healthcare Improvement Studies Institute. The Health Foundation is an independent charity committed to bringing about better health and healthcare for people in the United Kingdom. M.D.-W. is a senior investigator in the National Institute for Health Research (NF-SI-0617-10026). The views expressed in this article are those of the authors and not necessarily those of the NHS, the National Institute for Health Research, the Department of Health and Social Care, the Health Foundation, the Academy for Medical Sciences or the Wellcome Trust.

Previous presentation: This review was presented at the Society for Academic Primary Care Annual Scientific Meeting; July 10-12, 2018; London, England.

Key words: primary care; organization and administration; organizational efficiency; operations research; review

Acknowledgments: We gratefully acknowledge the expertise and assistance of Ms Veronica Phillips, Medical Librarian at the School for Clinical Medicine, University of Cambridge, UK.

Supplemental materials: Available at http://www.AnnFamMed. org/content/18/2/159/suppl/DC1/.

\section{References}

1. Allen D. Translational Mobilisation Theory: A new paradigm for understanding the organisational elements of nursing work. Int J Nurs Stud. 2018;79:36-42.

2. Tucker AL. The impact of operational failures on hospital nurses and their patients. J Oper Manage. 2004;22(2):151-169.

3. Tucker AL, Spear SJ. Operational failures and interruptions in hospital nursing. Health Serv Res. 2006;41(3 Pt 1):643-662.

4. Tucker AL, Heisler WS, Janisse LD. Designed for workarounds: a qualitative study of the causes of operational failures in hospitals. Perm J. 2014;18(3):33-41.

5. Starfield B, Leiyu S, Macinko J. Contribution of Primary Care to Health Systems and Health. Milbank Q. 2005;83(3):457-502.

6. Bowie $P_{1}$ Jeffcott $S$. Human factors and ergonomics for primary care. Educ Prim Care. 2016;27(2):86-93.

7. Hobbs FDR, Bankhead C, Mukhtar T, et al. Clinical workload in UK primary care: a retrospective analysis of 100 million consultations in England, 2007-14. Lancet.. 2016;387(10035):2323-2330.

8. Roland M, Everington S. Tackling the crisis in general practice. BMJ (Clinical research ed). 2016;352.

9. Dixon-Woods M, Cavers D, Agarwal S, et al. Conducting a critical interpretive synthesis of the literature on access to healthcare by vulnerable groups. BMC Med Res Methodol. 2006;6:35.

10. Charmaz K. Constructing Grounded Theory: A Practical Guide Through Qualitative Analysis. Thousand Oaks, CA. Sage Publications; 2006.

11. NVivo qualitative data analysis Software; QSR International Pty Ltd, In.

12. Dixon-Woods M. Systematic reviews and qualitative methods. In: Silverman D, ed. Qualitative research. 3rd ed. London, UK: Sage Publications; 2016. 
13. Wharton AS. The sociology of emotional labor. Annu Rev Sociol. 2009;35(1):147-165.

14. Hollnagel E. Why is work-as-imagined different from work-asdone? In: J. WRHEB, ed. Resilient Health Care: The Resilience of Everyday Clinical Work. Vol 2. Ashgate; 2015:249-264.

15. Hollnagel E, Wears RL, Braithwaite J. From safety-i to safety-ii: a white paper. The Resilient Healthcare Net. 2015.

16. Baron RJ, Fabens EL, Schiffman M, Wolf E. Electronic health records: just around the corner? Or over the cliff? Ann Intern Med. 2005;143(3):222-226.

17. Bouamrane MM, Mair FS. A study of general practitioners' perspectives on electronic medical records systems in NHSScotland. BMC Med Inform Decis Mak. 2013;13:58.

18. Goldberg DG, Kuzel AJ, Feng LB, DeShazo JP, Love LE. EHRs in primary care practices: Benefits, challenges, and successful strategies. Am J Manag Care. 2012;18(2):e48-e54.

19. Halas G, Singer A, Styles C, Katz A. New conceptual model of EMR implementation in interprofessional academic family medicine clinics. Can Fam Physician. 2015;61(5):e232-e239.

20. Howard J, Clark EC, Friedman A, et al. Electronic health record impact on work burden in small, unaffiliated, community-based primary care practices. J Gen Intern Med. 2013;28(1):107-113.

21. Koopman RJ, Steege LMB, Moore JL, et al. Physician information needs and electronic health records (EHRs): Time to reengineer the clinic note. J Am Board Fam Med. 2015;28(3):316-323.

22. McGeorge NM, Hegde S, Guarrera TK, et al. Studying the impact of interoperable electronic health records on workflow in ambulatory care. Int J Ind Ergon. 2015;49:144-155.

23. Weir CR, Staggers N, Gibson B, Doing-Harris K, Barrus R, Dunlea $R$. A qualitative evaluation of the crucial attributes of contextual information necessary in EHR design to support patient-centered medical home care. BMC Med Inform Decis Mak. 2015;15:30.

24. Richardson JE, Ash JS. A clinical decision support needs assessment of community-based physicians. J Am Med Inform Assoc. 2011;18(SUPPL. 1):28-35.

25. O'Malley AS, Draper K, Gourevitch R, Cross DA, Scholle SH. Electronic health records and support for primary care teamwork. J Am Med Inform Assoc. 2015;22(2):426-434.

26. Hayward J, Buckingham S, Thomson F, et al. "How long does it take?" A mixed methods evaluation of computer-related work in GP consultations. J Innovation Health Inform. 2015;22(4):409-425.

27. Al Alawi S, Al Dhaheri A, Al Baloushi D, Al Dhaheri M, Prinsloo EAM. Physician user satisfaction with an electronic medical records system in primary healthcare centres in Al Ain: A qualitative study. BMJ Open. 2014;4 (11) (e005569).

28. Samoutis G. Implementation of an electronic medical record system in previously computer-naive primary care centres: a pilot study from Cyprus. Inform Prim Care. 2007;15(4).

29. Friedman A, Crosson JC, Howard J, et al. A typology of electronic health record workarounds in small-to-medium size primary care practices. J Am Med Inform Assoc. 2014;21(E2):e78-e83.

30. Magrabi F, Liaw ST, Arachi D, Runciman W, Coiera E, Kidd MR. Identifying patient safety problems associated with information technology in general practice: An analysis of incident reports. BMJ Qual Saf. 2016;25(11):870-880.

31. Agha Z, Calvitti A, Ashfaq S, et al. EHR usability burden and its impact on primary care providers workflow. J Gen Intern Med. 2014;29:S82-583.

32. Holman GT, Beasley JW, Karsh BT, Stone JA, Smith PD, Wetterneck TB. The myth of standardized workflow in primary care. J Am Med Inform Assoc. 2016;23(1):29-37.

33. Hayward J, Thomson F, Milne H, et al. Too much, too late': Mixed methods multi-channel video recording study of computerized decision support systems and GP prescribing. J Am Med Inform Assoc. 2013;20(E1):e76-e84.
34. Vimalananda VG, Gupte G, Seraj SM. Electronic consultations (e-consults) to improve access to specialty care: a systematic review and narrative synthesis. J Telemed Telecare. 2015;21(6):323-330.

35. Crosson JC, Etz RS, Wu S, Straus SG, Eisenman D, Bell DS. Meaningful use of electronic prescribing in 5 exemplar primary care practices. Ann Fam Med. 2011;9(5):392-397.

36. Crosson JC, Schueth AJ, Isaacson N, Bell DS. Early adopters of electronic prescribing struggle to make meaningful use of formulary checks and medication history documentation. J Am Board Fam Med. 2012;25(1):24-32.

37. Jariwala KS, Holmes ER, Banahan BF III, McCaffrey DJ III. Adoption of and experience with e-prescribing by primary care physicians. Res Social Admin Pharm. 2013;9(1):120-128.

38. Weingart SN, Massagli M, Cyrulik $A$, et al. Assessing the value of electronic prescribing in ambulatory care: a focus group study. Int J Med Inform. 2009;78(9):571-578.

39. Kim Y, Chen AH, Keith E, Yee HF Jr, Kushel MB. Not perfect, but better: Primary care providers' experiences with electronic referrals in a safety net health system. J Gen Intern Med. 2009;24(5): 614-619.

40. Cohen GR, Adler-Milstein J. Meaningful use care coordination criteria: Perceived barriers and benefits among primary care providers. J Am Med Inform Assoc. 2016;23(e1):e146-e151.

41. Ozkaynak M, Johnson S, Shimada S, et al. Examining the Multilevel Fit between Work and Technology in a Secure Messaging Implementation. AMIA Annu Symp Proc. 2014:954-962.

42. Militello LG, Arbuckle NB, Saleem JJ, et al. Sources of variation in primary care clinical workflow: implications for the design of cognitive support. Health Informatics J. 2014;20(1):35-49.

43. Samaan ZM, Klein MD, Mansour ME, DeWitt TG. The impact of the electronic health record on an academic pediatric primary care center. J Ambul Care Manage. 2009;32(3):180-187.

44. Flanagan ME, Saleem JJ, Millitello LG, Russ AL, Doebbeling BN. Paper- and computer-based workarounds to electronic health record use at three benchmark institutions. J Am Med Inform Assoc. 2013;20(e1):e59-e66.

45. Lichtner V, Venters W, Hibberd R, Cornford T, Barber N. The fungibility of time in claims of efficiency: The case of making transmission of prescriptions electronic in English general practice. Int J Med Inform. 2013;82(12):1152-1170.

46. Lapane KL, Waring ME, Schneider KL, Dube C, Quilliam BJ. A mixed method study of the merits of e-prescribing drug alerts in primary care. J Gen Intern Med. 2008;23(4):442-446.

47. James KA, Ross SE, Vance B, Nath R, Harrison MI, West DR. Inefficiency in primary care: common causes and potential solutions. Fam Pract Manag. 2015;22(2):18-22.

48. Shipman SA, Sinsky CA. Expanding primary care capacity by reducing waste and improving the efficiency of care. Health Aff. 2013;32(11):1990-1997.

49. Tamblyn R, Huang A, Kawasumi $Y$, et al. The development and evaluation of an integrated electronic prescribing and drug management system for primary care. J Am Med Inform Assoc. 2006; 13(2):148-159.

50. Devine EB. Electronic prescribing at the point of care: A timemotion study in the primary care setting. Health Serv Res. 2010.

51. Hollingworth W, Devine EB, Hansen RN, et al. The Impact of e-Prescribing on Prescriber and Staff Time in Ambulatory Care Clinics: A Time-Motion Study. J Am Med Inform Assoc. 2007;14(6): 722-730.

52. Kripalani S, LeFevre F, Phillips CO, Williams MV, Basaviah P, Baker DW. Deficits in communication and information transfer between hospital-based and primary care physicians: implications for patient safety and continuity of care. JAMA. 2007;297(8):831-841. 
53. Smith PC, Araya-Guerra R, Bublitz C, et al. Missing clinical information during primary care visits. JAMA. 2005;293(5):565-571.

54. Redmond P, Carroll H, Grimes T, et al. GPs' and community pharmacists' opinions on medication management at transitions of care in Ireland. Fam Pract. 2016;33(2):172-178.

55. Armor BL, Wight AJ, Carter SM. Evaluation of adverse drug events and medication discrepancies in transitions of care between hospital discharge and primary care follow-up. J Pharm Pract. 2016; 29(2):132-137.

56. Groene RO, Orrego C, Sunol R, Barach P, Groene O. "It's like two worlds apart": an analysis of vulnerable patient handover practices at discharge from hospital. BMJ Qual Saf. 2012;21(Suppl 1):i67-i75.

57. Sellappans R, Lai PS, Ng CJ. Challenges faced by primary care physicians when prescribing for patients with chronic diseases in a teaching hospital in Malaysia: a qualitative study. BMJ Open. 2015;5(8):e007817.

58. Sinnott C, Mc Hugh S, Browne J, Bradley C. GPs' perspectives on the management of patients with multimorbidity: systematic review and synthesis of qualitative research. BMJ Open. 2013;3(9):e003610.

59. Jones $C D$, Vu MB, O’Donnell $C$, et al. A failure to communicate: Challenges and solutions to care coordination between hospitalists and primary care providers around hospitalizations. J Gen Intern Med. 2014;29:58.

60. Mastellos N, Car J, Majeed A, Aylin P. Using information to deliver safer care: a mixed-methods study exploring general practitioners' information needs in North West London primary care. J Innov Health Inform. 2014;22(1):207-213.

61. O'Malley AS, Tynan A, Cohen GR, Kemper N, Davis MM. Coordination of care by primary care practices: strategies, lessons and implications. Research brief. 2009(12):1-16.

62. Kljakovic M, Abernethy D, de Ruiter I. Quality of diagnostic coding and information flow from hospital to general practice. Inform Prim Care. 2004;12(4):227-234.

63. Poon EG, Gandhi TK, Sequist TD, Murff HJ, Karson AS, Bates DW. "I wish i had seen this test result earlier!": Dissatisfaction with test result management systems in primary care. Arch Intern Med. 2004;164(20):2223-2228.

64. Cutrona SL, Burns L, Fouayzi $H$, et al. It takes your whole life overPCP perspectives on electronic in basket notifications. J Gen Intern Med. 2017;32(2)(Supplement 1):S236.

65. Hysong SJ, Sawhney MK, Wilson L, et al. Provider management strategies of abnormal test result alerts: a cognitive task analysis. J Am Med Inform Assoc. 2010;17(1):71-77.

66. Murphy DR, Reis B, Sittig DF, Singh H. Notifications received by primary care practitioners in electronic health records: A taxonomy and time analysis. Am J Med. 2012;125(2):209.e201-209.e207.

67. Baron RJ. What's keeping us so busy in primary care? A snapshot from one practice. N Engl J Med. 2010;362(17):1632-1636.

68. Christensen T, Grimsmo A. Instant availability of patient records, but diminished availability of patient information: a multi-method study of GP's use of electronic patient records. BMC Med Inform Decis Mak. 2008;8:12.

69. Hickner J, Graham DG, Elder NC, et al. Testing process errors and their harms and consequences reported from family medicine practices: a study of the American Academy of Family Physicians National Research Network. Qual Saf Health Care. 2008;17(3): 194-200.

70. Sinsky CA, Willard-Grace R, Schutzbank AM, Sinsky TA, Margolius $D$, Bodenheimer $T$. In search of joy in practice: a report of 23 high-functioning primary care practices. Ann Fam Med. 2013;11(3):272-278.

71. Best RE, Hysong SJ, Pugh JA, Ghosh S, Moore Fl. Task overlap among primary care team members: an opportunity for system redesign? J Healthc Manag. 2006;51(5):295-306.
72. Chesluk BJ, Holmboe ES. How teams work-or don't-in primary care: a field study on internal medicine practices. Health Aff (Millwood). 2010;29(5):874-879.

73. Hung DY, Harrison MI, Martinez MC, Luft HS. Scaling lean in primary care: Impacts on system performance. Am J Manag Care. 2017;23(3):161-168.

74. Herring L. Lean experience in primary care. Qual Prim Care. 2009; 17(4):271-275

75. Crabtree BF, Nutting PA, Miller WL, et al. Primary care practice transformation is hard work: insights from a 15-year developmental program of research. Med Care. 2011;49(Suppl):S28-S35.

76. Stroebel CK, McDaniel RR, Crabtree BF, Miller WL, Nutting PA, Stange KC. How complexity Science Can Inform a Reflective Process for Improvement in Primary Care Practices. Jt Comm J Qual Patient Saf. 2005;31(8):438-446.

77. Linzer M, Manwell LB, Williams ES, et al. Working conditions in primary care: physician reactions and care quality. Ann Intern Med. 2009;151(1):28-36.

78. Sittig DF, Krall MA, Dykstra RH, Russell A, Chin HL. A survey of factors affecting clinician acceptance of clinical decision support. BMC Med Inform Decis Mak. 2006;6.

79. Zazove P, McKee M, Schleicher L, et al. To act or not to act: responses to electronic health record prompts by family medicine clinicians. J Am Med Inform Assoc. 2017;24(2):275-280.

80. Feldstein A, Simon SR, Schneider J, et al. How to design computerized alerts to safe prescribing practices. Jt Comm J Qual Saf. 2004;30(11):602-613.

81. Saleem JJ, Patterson ES, Militello L, Render ML, Orshansky G, Asch SM. Exploring barriers and facilitators to the use of computerized clinical reminders. J Am Med Inform Assoc. 2005;12(4):438-447.

82. Russ AL, Zillich AJ, McManus MS, Doebbeling BN, Saleem JJ. Prescribers' interactions with medication alerts at the point of prescribing: A multi-method, in situ investigation of the humancomputer interaction. Int J Med Inform. 2012;81(4):232-243.

83. Maniam N, Slight SP, Seger DL, et al. An evaluation of computerized medication alert override behavior in ambulatory care. J Gen Intern Med. 2014;29:S20.

84. Russ AL, Zillich AJ, McManus MS, Doebbeling BN, Saleem JJ. A human factors investigation of medication alerts: barriers to prescriber decision-making and clinical workflow. AMIA Annu Symp Proc. 2009;2009:548-552.

85. Davies P. The crowded consultation. Br J Gen Pract. 2012;62(605): 648-649.

86. Weingart SN, Simchowitz B, Shiman L, et al. Clinicians' assessments of electronic medication safety alerts in ambulatory care. Arch Intern Med. 2009;169(17):1627-1632.

87. Vaziri A, Connor E, Shepherd I, Jones RT, Chan T, de Lusignan $S$. Are we setting about improving the safety of computerised prescribing in the right way? A workshop report. Inform Prim Care. 2009;17(3):175-182.

88. Gaikwad R, Sketris I, Shepherd M, Duffy J. Evaluation of accuracy of drug interaction alerts triggered by two electronic medical record systems in primary healthcare. Health Informatics J. 2007; 13(3):163-177.

89. Lapane KL, Rosen RK, Dube C. Perceptions of e-prescribing efficiencies and inefficiencies in ambulatory care. Int J Med Inform. 2011;80(1):39-46.

90. Green LA, Nease D, Klinkman MS. Clinical reminders designed and implemented using cognitive and organizational science principles decrease reminder fatigue. J Am Board Fam Med. 2015;28(3): 351-359.

91. Curry L, Reed MH. Electronic decision support for diagnostic imaging in a primary care setting. J Am Med Inform Assoc. 2011; 18(3):267-270. 
92. O'Connor R, Barry N, Dempsey R. Interruptions in general practice. Ir Med J. 2007;100(9).

93. Chisholm CD, Dornfeld AM, Nelson DR, Cordell WH. Work interrupted: A comparison of workplace interruptions in emergency departments and primary care offices. Ann Emerg Med. 2001; 38(2):146-151.

94. Rhoades DR, McFarland KF, Finch WH, Johnson AO. Speaking and interruptions during primary care office visits. Fam Med. 2001; 33(7):528-532.

95. Dearden A. Interruptions during general practice consultations: the patients' view. Fam Pract. 1996;13(2):166-169.

96. Kumarapeli $P$, De Lusignan S. Using the computer in the clinical consultation; setting the stage, reviewing, recording, and taking actions: Multi-channel video study. J Am Med Inform Assoc. 2013; 20(E1):e67-e75.

97. Elmore N, Burt J, Abel G, et al. Investigating the relationship between consultation length and patient experience: a crosssectional study in primary care. Br J Gen Pract. 2016;66(653): e896-e903.

98. Paxton F. A study of interruption rates for practice nurses and GPs. Nurs Stand. 1996;10(43).

99. Shvartzman P, Antonovsky A. The interrupted consultation. Fam Pract. 1992;9(2):219-221.
100. Peleg R, Froimovici M, Peleg A, et al. Interruptions to the physician-patient encounter: An intervention program. Isr Med Assoc J. 2000;2(7):520-522.

101. Linzer M, Poplau S, Grossman E, et al. A cluster randomized trial of interventions to improve work conditions and clinician burnout in primary care: results from the Healthy Work Place (HWP) Study. J Gen Intern Med. 2015;30(8):1105-1111.

102. Linzer M, Poplau S, Brown R, et al. Do work condition interventions affect quality and errors in primary care? Results from the Healthy Work Place Study. J Gen Intern Med. 2017;32(1):56-61.

103. Brazil K, Wakefield DB, Cloutier MM, Tennen H, Hall CB. Organizational culture predicts job satisfaction and perceived clinical effectiveness in pediatric primary care practices. Health Care Manage Rev. 2010;35(4):365-371.

104. Perez HR, Beyrouty M, Bennett K, et al. Chaos in the clinic: characteristics and consequences of practices perceived as chaotic. J Healthc Qual. 2017;39(1):43-53.

105. Hughes EC. Men and Their Work. Toronto, Ontario: CollierMacmillan Canada Ltd; 1964.

106. Card AJ. Physician burnout: resilience training is only part of the solution. Ann Fam Med. 2018;16(3):267-270.

107. Kilo CM, Babineau M, Delio S, Binderman J. Improving efficiency in office practices. J Med Pract Manag. 2000;15(4):176-180. 